\title{
Early Childhood Caries and Certain Risk Factors in a Sample of Children
}

\section{1-3.5 Years in Tanta}

\section{Nahed A A Abu Hamila*}

Assistant Professor of Pedodontics, Department of Pedodontics, Tanta University, Egypt

\begin{abstract}
Early childhood caries (ECC) is the most common chronic disease in young children and may develop as soon as the teeth erupt. It affects the quality of life of families having affected children due to dental pain and subsequent tooth loss resulting in difficulty in eating, speaking, sleeping and socializing. It is a significant public health problem and certain segments of society. The purpose of this study was to assess prevalence of dental caries and identify some of risk factors among a sample of 1 - 3.5 years old Egyptian children. A sample of 560 children attending for Public Maternal and child health care and vaccination centers have participated in this study. Dental examination was performed by the author using the World Health Organization criteria for diagnosis of caries. Mothers completed a questionnaire on relevant factors as education, employment status, position of child in the family, type of child feeding and oral hygiene practice for both mothers and their children. The ECC was diagnosed in $69.6 \%$ of children. The mean dmft ranged from (2.1-7.6). Males were significantly affected more than females. Education level, employment status, oral hygiene practice for the mothers, position of child in the family, type of feeding and oral hygiene practice were dependently associated with the disease. The determinants of dental caries in Egyptian children were generally similar to those reported in other countries. The overall of the study indicated that mothers' education and attitude in maintaining oral hygiene of their children is very important determinant of early childhood caries and supported implementation of health promotion strategies that target new and expectant mothers. Immediate attention should be given to train the mothers with oral hygiene practices. Also, Dental care information and oral hygiene instructions should be given as early as possible to mothers including tooth brushing skills. It is important to continually follow changes in oral health of young children with repeated epidemiological studies to be able to institute necessary preventive measures.
\end{abstract}

Keywords: Early childhood caries; Risk factors; Prevalence of caries

\section{Introduction}

Early childhood caries (ECC) is the most common chronic disease in young children and may develop as soon as teeth erupt [1,2]. It is a multi-factorial disease that affects infants and toddlers, affecting their general health and growth pattern.

ECC affects the quality of life of families and their affected children due to dental pain and subsequent tooth loss resulting in difficulty in eating, speaking, sleeping and socializing [3,4]. It is a significant public health problem and certain segments of society [5]. It is defined as the presence of 1 or more decayed, missing or filled tooth surfaces in any primary tooth in child 71 months or younger [6]. A number of risk factors are associated with ECC, which can be broadly classified into biological and social risk factors [7]. Biological risk factors include nutritional variables, feeding habits and early colonization of cariogenic micro-organisms. Social risk factors comprise low parental education, low socio-economic status and lack of awareness about dental disease [8]. Not all dentists are trained to handle children and many general practitioners are not keen to treat young children [5]. Treatment necessitates extensive rehabilitation under general anesthesia and recurrence rates of caries are high thus requiring retreatment [9]. Hence, the dental profession favors a preventive approach towards management of ECC $[5,10]$. Therefore, developing an effective oral health promotion strategy in any given community must be based on an in-depth understanding of the unique needs of the population. A simple assessment of the knowledge, attitude and practice (behavior) levels may be the first step in identifying areas of weakness. The earliest form of prevention can be achieved by educating parents about ECC [11-14]. Hence, improving oral hygiene in early childhood requires that mothers' own tooth brushing habits and their infant oral cleaning skills are improved [15]. Prevention is the key for ECC treatment, and can be achieved successfully by knowledgeable and efficacious caregivers $[16,17]$. It is suggested that other models for disease initiation and progression needs to be explored besides known risk factors such as poor oral hygiene and diet control [18]. Parents' literacy in oral health is an important factor contributing to the overall health of children [1924]. Therefore, the purpose of this study was to assess the prevalence and severity of ECC as well as to investigate some associated risk factors.

\section{Material and Methods}

The sample of the present study comprised 560 toddlers (222 girls, 338 boys) aged (1-3.5) years and their mothers attending for Public Maternal health centers and centers for immunization in Gharbeia governorate, Tanta city, Egypt. The study was conducted from January 2013 till August 2013. Inclusion criteria were normal healthy children aged (1-3.5) years. The children aged one year who are included in the study had at least one erupted tooth. Children with medical problems, predentulous infants, those with less than two thirds of the crown erupted and children whose mothers refused to take part in the study were excluded from the study. Questionnaires were administered to the mothers of participating children to obtain socio-demographic information as: name, sex, birth date, and position of the child in the family, mother's level of education and employment status. Mothers education level were categorized into three levels; Low: primary school or Illiterate, moderate: diploma or high school education and high: university education. Also, biologic risk factors as feeding habits of the

*Corresponding author: Dr. Nahed A A Abu Hamila, Assistant Professor of Pedodontics, Department of Pedodontics, Tanta University, Egypt, Tel: +201223334430; E-mail: dr nahed2009@hotmail.com

Received November 16, 2013; Accepted December 18, 2013; Published December 20, 2013

Citation: Abu Hamila NAA (2013) Early Childhood Caries and Certain Risk Factors in a Sample of Children 1-3.5 Years in Tanta. Dentistry 4: 180. doi:10.4172/2161 1122.1000180

Copyright: ( $) 2013$ Abu Hamila NAA. This is an open-access article distributed under the terms of the Creative Commons Attribution License, which permits unrestricted use, distribution, and reproduction in any medium, provided the original author and source are credited. 
children and oral health practices for both mothers and children were also recorded. Mothers own oral cleaning was assessed in terms of the frequency of their own tooth brushing. The answers to the questions were categorized into: no brushing, brushing once/daily, twice/daily and three times daily. The same terms were used to assess the mothers cleaning for their children. Mother responded with: no brushing was asked about the cause. Responses of the mothers regarding inability to maintain oral hygiene of their children were categorized into: "I don't know how to brush", "I don't have time" and "I cannot make cleaning for the child" [15]. Clinical diagnosis of ECC was based on intraoral examinations conducted in a well lit area by the same examiner NAA using disposable plane dental mirrors and wooden tongue depressors in natural light according to WHO guidelines. The mothers helped to restrain the infant movement during examination. The dental caries status was assessed using the $\mathrm{dmft}$ index. All erupted teeth were examined using a modification of WHO criteria with initial carious lesions (white spots) being included in the $\mathrm{dmft}$ values. Then teeth were considered decayed if there was any evidence of dental caries (white spot lesions or cavitations), including filled teeth with recurrent caries.

Questionnaires were fulfilled by the author through direct interview with the participating mothers of children. Data were collected, recorded in standardized form and entered into SPSS software for statistical analysis. Chi-square was used to identify factors with significant association with dental caries. The minimal sample 323 by type 1 error $5 \%$ and power of test $90 \%$.

\section{Results}

Table 1 shows the relation of early childhood caries and certain related factors for children (age, sex, position of the child in the family and type of feeding). Also, some factors related to mothers were also studied as educational level and employment status.

The results showed that of 560 examined children, 390 have dental caries with a prevalence of $(69.6 \%)$. Thus, $30.4 \%$ of children were classified as caries free (i.e. without any clinical manifested lesion) in the primary dentition.

As regard sex, ECC significantly affects males more than females (77.5\% vs. $57.6 \%) \mathrm{P}<0.001$

The results showed that the selected risk factors were significantly associated with ECC. As regard age, young children from (1-2) years showed the least percent of ECC. On the other hand, it was noted that there was a significant increase in caries in the older groups.

In relation to the position of child in the family, the results revealed that ECC was significantly evidenced in all children whatever their positions $(\mathrm{P}<0.001)$.

As regard employment status of the mothers, the results showed that most of currently employed mothers having more children with ECC (74.6\%).

Furthermore, educational level of the mothers was also evaluated as risk factor for ECC. The results revealed significant association between educational level of the mother and ECC. The results showed that ECC was significantly higher in children with low education level of their mothers.

In relation to type of feeding as a risk factor for ECC, the results revealed that ECC significantly affect children with bottle feeding alone followed by those with breast feeding alone. On the other hand,

\begin{tabular}{|c|c|c|c|c|c|c|c|c|}
\hline & \multicolumn{2}{|c|}{ Total } & \multicolumn{2}{|c|}{ Caries Free } & \multicolumn{2}{|c|}{ Caries } & \multicolumn{2}{|c|}{ Chi-square } \\
\hline & $\mathbf{N}$ & $\%$ & $\mathbf{N}$ & $\%$ & $\mathbf{N}$ & $\%$ & $\mathrm{X}^{2}$ & P-value \\
\hline \multicolumn{9}{|l|}{ Age } \\
\hline $1-1.5$ yrs & 49 & 8.75 & 41.00 & 83.67 & 8.00 & 16.33 & \multirow{5}{*}{157.416} & \multirow{5}{*}{$<0.001^{*}$} \\
\hline $1.5-2$ yrs & 60 & 10.71 & 46.00 & 76.67 & 14.00 & 23.33 & & \\
\hline $2-2.5$ yrs & 98 & 17.50 & 19.00 & 19.39 & 79.00 & 80.61 & & \\
\hline $2.5-3 \mathrm{yrs}$ & 163 & 29.11 & 28.00 & 17.18 & 135.00 & 82.82 & & \\
\hline $3-3.5$ yrs & 190 & 33.93 & 36.00 & 18.95 & 154.00 & 81.05 & & \\
\hline \multicolumn{9}{|l|}{ Sex } \\
\hline Female & 222 & 39.64 & 94.00 & 42.34 & 128.00 & 57.66 & \multirow{2}{*}{24.991} & \multirow{2}{*}{$<0.001^{\star}$} \\
\hline Male & 338 & 60.36 & 76.00 & 22.49 & 262.00 & 77.51 & & \\
\hline \multicolumn{9}{|l|}{ Position of child } \\
\hline Only & 45 & 8.04 & 7.00 & 15.56 & 38.00 & 84.44 & \multirow{4}{*}{56.243} & \multirow{4}{*}{$<0.001^{*}$} \\
\hline Eldest & 238 & 42.50 & 61.00 & 25.63 & 177.00 & 74.37 & & \\
\hline Mid & 107 & 19.11 & 64.00 & 59.81 & 43.00 & 40.19 & & \\
\hline Young & 170 & 30.36 & 38.00 & 22.35 & 132.00 & 77.65 & & \\
\hline \multicolumn{9}{|l|}{ Employment status } \\
\hline Current employed & 386 & 68.93 & 98.00 & 25.39 & 288.00 & 74.61 & \multirow{2}{*}{14.506} & \multirow{2}{*}{$<0.001^{*}$} \\
\hline Unemployed & 174 & 31.07 & 72.00 & 41.38 & 102.00 & 58.62 & & \\
\hline \multicolumn{9}{|l|}{ Education level } \\
\hline High & 286 & 51.07 & 92.00 & 32.17 & 194.00 & 67.83 & \multirow{3}{*}{9.434} & \multirow{3}{*}{$0.009^{*}$} \\
\hline Moderate & 106 & 18.93 & 41.00 & 38.68 & 65.00 & 61.32 & & \\
\hline Low & 168 & 30.00 & 37.00 & 22.02 & 131.00 & 77.98 & & \\
\hline \multicolumn{9}{|l|}{ Type of feeding } \\
\hline Breast feeding & 206 & 36.79 & 61.00 & 29.61 & 145.00 & 70.39 & \multirow{4}{*}{11.191} & \multirow{4}{*}{$0.011^{*}$} \\
\hline Bottle fed. & 191 & 34.11 & 47.00 & 24.61 & 144.00 & 75.39 & & \\
\hline Both & 80 & 14.29 & 36.00 & 45.00 & 44.00 & 55.00 & & \\
\hline Weaned & 83 & 14.82 & 26.00 & 31.33 & 57.00 & 68.67 & & \\
\hline
\end{tabular}

Table 1: Relationship of early childhood caries and certain related factors. 
children with both breast and bottle feeding together were the least affected by ECC.

Table 2 shows the mean values of $\mathrm{dmft}$ in both male and female children at different age groups. The mean values were ranged from (2.1-7.6). The results showed that dmft increased with age in both male and female children but this increase was insignificant at (1-2) years. On the other hand, there was a significant increase of ECC in male children at age (2-2.5) years and (3-3.5) years $\mathrm{P}<0.001$ (Figure 1 ).

Oral hygiene practices by the mothers for themselves and for their children are represented in Table 3 . The results revealed that when the children at (1-1.5 years) $69 \%$ of mothers neglect their oral hygiene and don't brush their teeth, while $30 \%$ brush once daily. On the other hand, the results showed that none of the mothers brush twice or 3 times daily. At age (1.5-2) years the percent of practicing oral hygiene by the mothers increased; so, $56.5 \%$ brush once $38 \%$ with don't brush their teeth at all, only $5 \%$ brush twice daily and non of the mothers clean 3 times daily (Table 3 ).
Additionally, at (2-2.5) years, it was evident that considerable percent $(43 \%)$ of mothers again neglect the practice of teeth brushing while $40 \%$ clean once daily and $13 \%$ clean twice daily. Performance of brushing three times daily had the least percent (2\%).

Additionally, the same results were obtained at the age of (2.5-3) years. So, neglecting dental brushing was the main feature (34\%) and the least percent was for practicing brushing 3 times daily (Table 3 ). At the age of (3-3.5) years, the number of mothers practising brushing was increased. As regard the cleaning of children teeth by their mothers, the results revealed that many children don't receive brushing for their teeth at all ages. It was noted that as the child gets older, the mothers care of brushing increases. Table 4 shows mothers responses to the statements regarding inability to maintain oral hygiene to their children. 32.9\% of mothers responses were:" I don't know how to brush the child teeth" and $13.7 \%$ responses were: "we have no time to brush the child teeth" and the greatest percent $53.3 \%$ of responses were: "we can't make cleaning for the child". When compare between the three

\begin{tabular}{|c|c|c|c|c|c|c|c|c|c|c|}
\hline \multirow[b]{2}{*}{ dmft } & \multicolumn{4}{|c|}{ Male } & \multicolumn{4}{|c|}{ Female } & \multicolumn{2}{|c|}{ T-test } \\
\hline & $\mathbf{N}$ & $\begin{array}{c}\text { Mean } \\
\text { dmft }\end{array}$ & \pm & SD & $\mathbf{N}$ & $\begin{array}{c}\text { Mean } \\
\text { dmft }\end{array}$ & \pm & SD & $t$ & P-value \\
\hline 1-1.5yrs & 5 & 2.800 & \pm & 0.85 & 3 & 2.1 & \pm & 0.8744 & 1.117 & 0.306 \\
\hline $1.5-2 y r s$ & 9 & 3.600 & \pm & 1.01 & 5 & 2.2 & \pm & 0.954 & 1.933 & 1.933 \\
\hline 2-2.5yrs & 53 & 6.500 & \pm & 1.5 & 26 & 4.3 & \pm & 1.2115 & 6.504 & $<0.001^{*}$ \\
\hline 2.5-3yrs & 98 & 4.500 & \pm & 1.6 & 37 & 4.1 & \pm & 1.054 & 1.156 & 0.2514 \\
\hline 3-3.5yrs & 97 & 7.600 & \pm & 1.2 & 57 & 5.3 & \pm & 1.64 & 7.071 & $<0.001^{*}$ \\
\hline
\end{tabular}

Table 2: The mean values of (dmft) of children in relation to age.

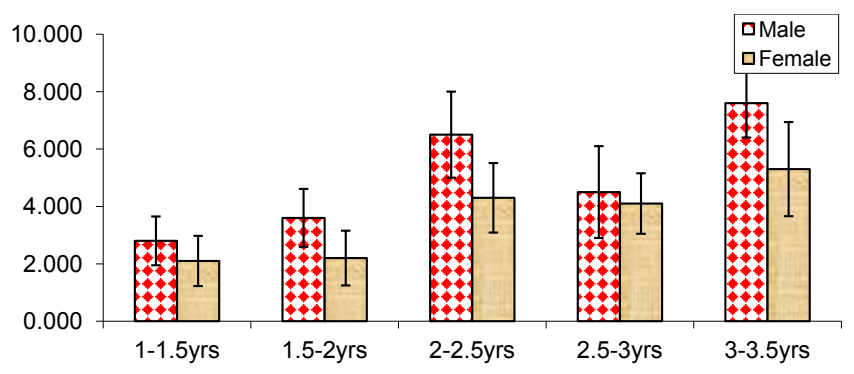

Figure 1: The mean values of (dmft) in both male and female children at different age groups.

\begin{tabular}{|c|c|c|c|c|c|c|c|c|c|c|c|c|}
\hline & & \multirow[b]{2}{*}{ Total } & \multicolumn{4}{|c|}{ Mothers } & \multicolumn{4}{|c|}{ Child } & \multicolumn{2}{|c|}{ Chi-square } \\
\hline & & & $\begin{array}{c}\text { No } \\
\text { Brushing }\end{array}$ & $\begin{array}{l}\text { Brushing } \\
\text { once daily }\end{array}$ & $\begin{array}{l}\text { Brushing } \\
\text { twice daily }\end{array}$ & $\begin{array}{l}\text { Brushing } \\
3 \text { /daily }\end{array}$ & $\begin{array}{c}\text { No } \\
\text { Brushing }\end{array}$ & $\begin{array}{l}\text { Brushing } \\
\text { once daily }\end{array}$ & $\begin{array}{l}\text { Brushing } \\
\text { twice daily }\end{array}$ & $\begin{array}{l}\text { Brushing } \\
\text { 3/daily }\end{array}$ & $x^{2}$ & P-value \\
\hline \multirow{2}{*}{$1-1.5$} & $\mathbf{N}$ & 49 & 34 & 15 & 0 & 0 & 48 & 1 & 0 & 0 & \multirow{2}{*}{14.640} & \multirow{2}{*}{$<0.001^{*}$} \\
\hline & $\%$ & 8.75 & 69.39 & 30.61 & 0.00 & 0.00 & 97.96 & 2.04 & 0.00 & 0.00 & & \\
\hline \multirow{2}{*}{$1.5-2 y r s$} & $\mathbf{N}$ & 60 & 23 & 34 & 3 & 0 & 42 & 10 & 8 & 0 & \multirow{2}{*}{20.917} & \multirow{2}{*}{$<0.001^{*}$} \\
\hline & $\%$ & 10.71 & 38.33 & 56.67 & 5.00 & 0.00 & 70.00 & 16.67 & 13.33 & 0.00 & & \\
\hline \multirow{2}{*}{$2-2.5 y r s$} & $\mathbf{N}$ & 98 & 43 & 40 & 13 & 2 & 69 & 20 & 9 & 0 & \multirow{2}{*}{15.430} & \multirow{2}{*}{$<0.001^{*}$} \\
\hline & $\%$ & 17.50 & 43.88 & 40.82 & 13.27 & 2.04 & 70.41 & 20.41 & 9.18 & 0.00 & & \\
\hline \multirow{2}{*}{$2.5-3 y r s$} & $\mathbf{N}$ & 163 & 56 & 36 & 50 & 21 & 99 & 51 & 11 & 2 & \multirow{2}{*}{55.145} & \multirow{2}{*}{$<0.001^{*}$} \\
\hline & $\%$ & 29.11 & 34.36 & 22.09 & 30.67 & 12.88 & 60.74 & 31.29 & 6.75 & 1.23 & & \\
\hline \multirow{2}{*}{$3-3.5 y r s$} & $\mathbf{N}$ & 190 & 59 & 45 & 63 & 23 & 106 & 60 & 22 & 2 & \multirow{2}{*}{52.947} & \multirow{2}{*}{$<0.001^{*}$} \\
\hline & $\%$ & 33.93 & 31.05 & 23.68 & 33.16 & 12.11 & 55.79 & 31.58 & 11.58 & 1.05 & & \\
\hline \multirow{2}{*}{ Total } & $\mathbf{N}$ & 560 & 215 & 170 & 129 & 46 & 364 & 142 & 50 & 4 & \multirow{2}{*}{111.002} & \multirow{2}{*}{$<0.001^{*}$} \\
\hline & $\%$ & 100.00 & 38.4 & 30.4 & 23.0 & 08.2 & 65.0 & 25.4 & 08.9 & 00.7 & & \\
\hline \multirow{2}{*}{\multicolumn{2}{|c|}{ Chi-square }} & $X^{2}$ & \multicolumn{4}{|c|}{117.49} & \multicolumn{4}{|c|}{52.37} & & \\
\hline & & P-value & \multicolumn{4}{|c|}{$<0.001^{*}$} & \multicolumn{4}{|c|}{$<0.001^{*}$} & & \\
\hline
\end{tabular}

Table 3: Frequency of Oral hygiene practice for both mothers and their children. 


\begin{tabular}{|c|c|c|c|}
\hline \multicolumn{2}{|l|}{ Mothers responses } & $\mathbf{N}$ & $\%$ \\
\hline \multicolumn{2}{|l|}{ I don't know how to brush } & 120 & 32.97 \\
\hline \multicolumn{2}{|l|}{ I don't have time } & 50 & 13.74 \\
\hline \multicolumn{2}{|l|}{ I can't make cleaning for child } & 194 & 53.30 \\
\hline \multicolumn{2}{|l|}{ Total } & 364 & 100.00 \\
\hline \multirow{2}{*}{ Chi-square } & $\mathrm{X}^{2}$ & \multicolumn{2}{|c|}{85.473} \\
\hline & P-value & \multicolumn{2}{|c|}{$<0.001^{*}$} \\
\hline
\end{tabular}

Table 4: Mothers responses to the statements regarding inability to maintain ora hygiene to their children.

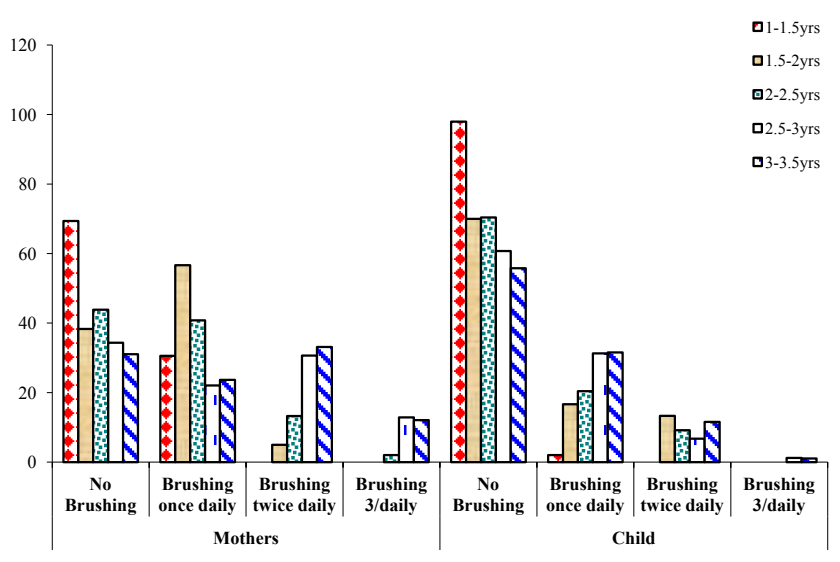

Figure 2: Illustrates teeth brushing for mothers and their children in different age groups.

responses of the mothers, there was a significant difference between the three responses $(\mathrm{P}<0.05)$ (Figure 2).

\section{Discussion}

The oral health status is dependent on the interaction of multiple etiological and predisposing factors, which have varying abilities to cause diseases. An analysis of caries in this study demonstrated that a significant proportion of infants and toddlers are still affected by the disease. The prevalence of ECC among children aged 1-3.5 years in the present study was $69.6 \%$ in the tested sample. This result was inconsistent with [25] who had a prevalence of $26.5 \%$ among children in Saudi Arabia and [26] that had a prevalence of $40 \%$. In addition, the prevalence of this study is approximated with the study of Oral health surveys of pre-school children in Malaysia. It showed caries prevalence of $76.2 \%$ and $74.5 \%$ in 2007 and 2009 respectively $[27,28]$. On the other hand, the prevalence of ECC reported in the present study is decreased than study of [29] who reported that more than $92 \%$ of children had caries in their primary teeth. The difference in caries prevalence is attributed to the fact that etiology of ECC is complex and there are several unexplained interactions. Also, it may be due to poor knowledge, attitudes and practice towards factors associated with ECC in different populations. In addition, the lack of an organized preventive oral health care system, limited accessibility to preventive and treatment services and insufficient scientific knowledge may have a role (Figure 3).

The results showed also that ECC significantly affects males more than females. This result corroborates the results from previous studies of $[25,30]$ who reported that there was significant affection of male more than female children. On the other hand, this result contradicted ${ }^{26}$ who found no difference between boys and girls $(\mathrm{P}=0.409)$.

In the present study, all attending children to Immunization centers who fulfilled the inclusion criteria were included in the present study along 8 months period regardless their sex. So, this finding may have some bias (boys were more than girls in the study sample).

The findings of this study showed that the older the child the more the ECC occurrence. This finding is consisted with [26,31-33]. The increase in caries prevalence may be attributed to between-meal snacks, sweetened beverages and sweets in the older children.

The present findings confirm the high $\mathrm{dmft}$ and caries prevalence reported in the last decade among children $[27,28,32]$.

The present results showed that $\mathrm{dmft}$ increase with age in both male and female children but this increase is insignificant from (1-2) years then becomes significant in male children at age (2-2.5) years and (3-3.5) years. This finding is consistent with the study of [26,34] who reported increased prevalence of children with high caries experience with age. This increase in prevalence is partly due to the lack of an organized preventive oral health care system, limited accessibility to prevention or the inability of practitioners to provide care for young children.

In the present study, position of the child in the family, mothers level of education and employment status were studied as risk factors for ECC The results showed that these factors are important determinants of ECC. An increase in caries prevalence was observed in children whose mothers presented the lowest level of education. This is in accordance with the studies of $[25,26,31,33]$ who confirmed that maternal level of education is a good predictor of dental caries in childhood. Contrary to these studies, the study of [35] who reported no association between parental education and dental caries. The study results revealed that ECC significantly affects children of currently employed mothers. This may be attributed to the fact that employed mothers are busy forwarding their careers; juggling family and professional responsibilities are not always easy tasks. Moreover, the widespread belief that primary teeth are temporary and not as important as permanent teeth is likely to be higher among mothers of all educational levels. The inter sibling relationship was also studied and the results revealed that the only and latest children had the highest percent of caries. These results in accordance with [14] and contradicted those of [36]. They commented that the only child is the one to whom nothing is refused. They added, when the number of siblings is high, the attitude shown by the parents varies significantly. The mother unequal to the task of coping adequately with the overlarge household and she has no time to coddle her latest born.

As regard to feeding pattern, the findings of the present study were similar to that reported in other studies [34,35,37-40] who reported

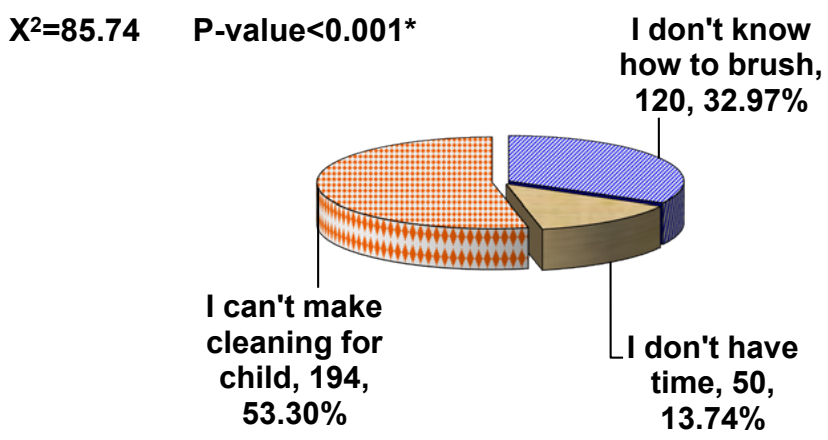

Figure 3: Illustrates mother's responses towards the inability to maintain oral hygiene to their children. 
that both bottle and breast feeding are risk factors for ECC. On the other hand, this finding was contradicted with [25] who reported that feeding pattern did not show association with ECC $[36,41]$. Their studies reported that breast feeding plays a preventive role in colonization of $S$. mutans. Difference in the results may be explained by the difference in mothers concern with children oral hygiene behaviors, their knowledge, education and genetics in the different populations [42].

One of the factors identified as probably influencing dental health and diseases in children is the practice and attitude of dental care. In the present study, mothers' practices of oral hygiene for themselves and for their children were studied as a risk factor for dental caries. This is because mothers play a key role in health care of the young children who are usually unable to make brushing for their own teeth and are dependent on their caregivers for their day to day care.

So, mothers then become a major possible modifier of factors that could impact the oral health of the child in the short and long-term. The results revealed that the main bulk of mothers in the study sample were neglecting the practice of dental brushing for themselves and for their children. When compared between the practice of brushing for the mothers and their children, the results showed an alarming finding. There is significant decrease in practice of brushing for young children. The results contradicted the study conducted in Nigeria and found that mothers play a significant role in the care and health of their children [33]. This maternal attitude is associated with better oral hygiene status in Nigerian pre-school children.

The results of this study revealed that $30.4 \%$ of mothers brush their teeth once daily and $31.2 \%$ brush more than once. These results are inconsistent with [15] who reported that $57 \%$ of mothers brush once a day and $11 \%$ more than once a day. This difference may be due to difference in educational level, diet habits, social, economical background and family responsibilities.

On the other hand, the results reported that the older of child the increase the practice of oral hygiene by the mothers. This finding is consistent with [15]. However, the results of this study revealed negative association between the frequencies of the mothers own cleaning and cleaning for their children. The frequency of oral cleansing in the present child population was at very low level compared to data reported from developed countries. Tooth brushing which is a part of the recommended oral self-care but scarcely reported for our children is practiced almost as a norm for 1-4 years old children (85-97\%) in several Nordic countries and in the USA, with the highest figure reported in Scotland $[42,43]$.

Our finding on child's oral cleaning are however, comparable to those reported for some Middle Eastern countries as Jordan [31,44] but lower than for other countries like Poland and Hong Kong $[45,46]$. Our mothers had better attitude, but did not necessarily have better practices.

The responses of the mothers to three statements describing mothers' perception of their ability towards maintaining the child's oral hygiene. The results revealed that $53.3 \%$ of mothers responded by: (I cannot make cleaning for the child). The results of this study highlighted serious weaknesses in the practices of oral hygiene for young children as those lack the ability to clean their own teeth effectively. This result contradicted with [15] who reported that $59 \%$ of all mothers stated that:

"They did not know how to brush or clean their children's teeth". Additionally, the results showed also that $13.7 \%$ did not have time to brush the teeth of their children. This is contradicted with the results of [15] where the mothers confirmed that they had time to clean their children's teeth and $82 \%$ disagreed with the statement. This response in this study may be due to knowledge of infant oral health-related concepts were much weaker as the primary teeth will be replaced soon by permanent teeth, possibly due to the fact that, in Egypt, infant oral health-related messages, oral health promotion and prenatal oral health education programs are rarely encountered in the local media or local health care setups than in many other parts of the world as the UK, and North America (USA and Canada) [30]. Also, Lack of training and unfamiliarity with oral health issues may make it difficult for mothers to assume a more active role in the oral health promotion of children. Other factors are, however, recognized as having an impact on the maternal dental health knowledge and attitudes such as cultural beliefs, social norms and responsibilities $[40,47,48]$.

The literature has emphasized the need for more cross-sectional studies starting from the earliest possible age in order to provide information regarding how to promote infant oral health, as well as identifying infants and toddlers who are at risk of developing childhood caries to be targeted for specific effective preventive measures in our community.

Further studies with larger number of children may properly clarify the association of dental caries parameters.

\section{Conclusion}

1. ECC prevalence was $69.6 \%$ in Tanta infants and males affected more than females.

2. The greatest increase in caries prevalence and $\mathrm{dmft}$ was observed between (2-2.5) years and (3-3.5) years of age.

3. Within the limitation of this study, among the various factors investigated the mother's level of education, employment status, position of the child in the family and infant feeding habits and all were found to have significant effects on the development of ECC.

4. There was significant decrease in practice of brushing for both young children and their mothers.

5. Mothers' perception of their ability towards maintaining the child's oral hygiene revealed that the most of Egyptian mothers stated that:" they couldn't make cleaning for their children".

\section{Recommendations}

1. Increasing caries prevalence in the primary dentition requires immediate attention and repeated epidemiological studies to be able to institute necessary preventive measures and treatment services for young children.

2. The increase in caries index at young age indicating that community-based programs and professional care should begin early in the first year of life to assess feeding, hygiene practices and identify incipient lesions before this condition becomes too advanced to prevent, difficult and expensive to treat.

So, the study suggests that teeth examination should be obligatory and may be added to immunization schedule of child (an official form) may have a role in prevention, early detection and treatment of ECC.

3. The extent of oral health education and regular training of the mothers to perform cleaning of the teeth for their children by dentists and health care givers should be encouraged. 
Citation: Abu Hamila NAA (2013) Early Childhood Caries and Certain Risk Factors in a Sample of Children 1-3.5 Years in Tanta. Dentistry 4: 180. doi:10.4172/2161-1122.1000180

4. The expansion of mother education activity to include expectant as well as young women which aims at training parents who has definite need of advice to recognize ECC early and seek early treatment.

5. Mothers with low levels of education may require special attention because their children are of greater risk of caries and would benefit most from preventive efforts.

\section{References}

1. Johnson DC, Nowjack-Raymer R (1989) Baby bottle tooth decay (BBTD): issues, assessment, and an opportunity for the nutritionist Am Dietetic Assoc 89: $1112-1116$

2. Douglass JM, Douglass AB, Silk HJ (2004) A Practical Guide to Infant Ora Health. Am Fam Physician 70: 2113-2120.

3. Edelstein B, Vargas CM, Candelaria D, Vemuri M (2006) Experience and Policy Implications of Children Presenting with Dental Emergencies to Us Pediatric Dentistry Training Programs. Pediatr Dent 28: 431-437.

4. Pahel BT, Rozier RG, Slade GD (2007) Parental Perceptions of Children's Ora Health: The Early Childhood Oral Health Impact Scale (ECOHIS). Health Qual Life Outcomes 5: 6 .

5. Vargas CM, Ronzio CR (2006) Disparities in Early Childhood Caries. BMC Ora Health 6: S3.

6. Drury TF, Horowitz AM, Ismail AI, Maertens MP, Rozier RG, et al. (1999) Diagnosing and Reporting Early Childhood Caries for Research Purposes. J Public Health Dent 59: 192-197.

7. Berg JH, Slayton RL (2009) Early Childhood Oral Health. Wiley-Blackwell, Singapore.

8. Hallett KB, O'Rourke PK (2003) Social and Behavioral Determinants of Early Childhood Caries. Aust Dent J 48: 27-33.

9. Almeida AG, Roseman MM, Sheff M, Huntington N, Hughes CV (2000) Future Caries Susceptibility in Children with Early Childhood Caries Following Treatment under General Anesthesia. Pediatr Dent 22: 302-306.

10. Ismail Al (2003) Determinants of Health in Children and the Problem of Early Childhood Caries. Pediatr Dent 25: 328-333

11. Clarke P, Fraser-Lee NJ, Shimono T (2001) Identifying Risk Factors for Predicting Caries in School-Aged Children Using Dental Health Information Collected at Preschool Age. ASDC J Dent Child 68: 373-378.

12. Savage MF, Lee JY, Kotch JB, Vann WF (2004) Early Preventive Dental Visits (Effects on Subsequent Utilization and Costs). Pediatrics 114: e418-423.

13. Plutzer K, Spencer AJ (2008) Efficacy of an Oral Health Promotion Intervention in the Prevention of Early Childhood Caries. Community Dent Oral Epidemiol 36: $335-346$.

14. Meyer K, Geurtsen W, Gunay H (2010) An Early Oral Health Care Program Starting During Pregnancy: Results of a Prospective Clinical Long-Term Study. Clin Oral Investig 14: 257-264.

15. Mohebbi SZ, Virtanen JI, Murtomaa H, Vahid-Golpayegani M, Vehkalaht MM (2008) Mothers as Facilitators of Oral Hygiene in Early Childhood. Int J Paediatr Dent 18: 48-55.

16. Finlayson TL, Siefert K, Ismail AI, Delva J, Sohn W (2005) Reliability and Validity of Brief Measures of Oral Health-Related Knowledge, Fatalism, and Self-Efficacy in Mothers of African American Children. Pediatr Dent 27: 422428.

17. Finlayson TL, Siefert K, Ismail Al, Sohn W (2007) Maternal Self-Efficacy and 1-5-Year-Old Children's Brushing Habits. Community Dent Oral Epidemiol 35: 272-281.

18. Hallett KB (2000) Early Childhood Caries-A New Name for an Old Problem. Ann R Austral as Coll Dent Surg 15: 268-275

19. Blinkhorn AS, Wainwright-Stringer YM, Holloway PJ (2001) Dental Health Knowledge and Attitudes of Regularly Attending Mothers of High-Risk, PreSchool Children. Int Dent J 51: 435-438.

20. Singh P, King $T$ (2003) Infant and Child Feeding Practices and Dental Caries in 6 to 36 Months Old Children in Fiji. Pac Health Dialog 10: 12-16.
21. Orenuga OO, Sofola OO (2005) Survey of the Knowledge, Attitude and Practices of Antenatal Mothers in Lagos, Nigeria about the Primary Teeth. Afr J Med Med Sci 34: 285-291.

22. Da Silva K (2007) Role for the Family in Children's Oral Health. N Y State Dent J 73: $55-57$.

23. Gussy MG, Waters EB, Riggs EM, Lo SK, Kilpatrick NM (2008) Parental Knowledge, Beliefs and Behaviors for Oral Health of Toddlers Residing in Rura Victoria. Aust Dent J 53: 52-60.

24. Hoeft KS, Barker JC, Masterson EE (2010) Urban Mexican-American Mothers:Beliefs About Caries Etiology in Children. Community Dent Oral Epidemiol 38: 244

25. Sabbah WA, Stewart BL, Owusu-Agyakwa GB (2003) Prevalence and Determinants of Caries Among 1-5 year-old Saudi Children in Tabuk, Saudi Arabia. Saudi Dent J 15: 131-135.

26. Ferreira SH, Beria JU, Kramer PF, Feldens EG, Feldens CA (2007) Denta Caries in 0-5 year-old Brazilian Children: Prevalence, Severity and associated factors. Int J of Pediatr Dent 17: 289-296.

27. Oral Health Division, Ministry of Health Malaysia (2007) The National Oral Health Survey of Preschool Children. Government printers, Kuala Lumpur.

28. Oral Health Division, Ministry of Health Malaysia (2009) National Oral Health Survey of School Children. Government printers, Kuala Lumpur.

29. Stewart BL, Al Juhani TS, Al Akeel AS, Al Brikeet HA, Al Buhairan WH, et al. (2000) Caries experience in grades 1 and 6 children attending elementary schools in King Abdul-Aziz Military City, Tabuk, Saudi Arabia. Saudi Dent J 12: 140-148.

30. Chan SC, Tsai JS, King NM (2002) Feeding and Oral Hygiene Habits of Preschool Children in Hong Kong and Their Caregivers' Dental Knowledge and Attitudes. Int J Paediatr Dent 12: 322-331.

31. Rajab LD, Hamadan MAM (2002) Early Childhood Caries and risk factors in Jordan. Community Dent Health 19: 224-229.

32. Kiwanuka SN, Astrom AN, Trovik TA (2004) Dental Caries experience and its relationship to social and behavioral factors among 3-5 years old children in Uganda. Int J Pediatr Dent 14: 336-346.

33. Abiola Adeniyi A, Eyitope Ogunbodede O, Sonny Jeboda O, Morenike Folayan OD (2009) Maternal Factors Influence the Dental Health Status of Nigerian School Children. Int J Paediatr Dent 19: 448-454.

34. Ozer S, Sen Tunc E, Bayrak S, Egilmez T (2011) Evaluation of certain risk factors for early childhood caries in Samsun, Turky. Eur J Pediatr Dent 12:103106.

35. Cogulu D, Ersin NK, Uzel A, Eronat N, Aksit S (2008) A long-Term Effect of Caries-Related Factors in Initially Caries - Free Children. Int $\mathrm{J}$ of Pediatr Dentistry 18: 361-367.

36. Oulis CJ, Berdouses ED, Vadiakas G, Lygidakis NA (1999) Feeding practices of Greek children with and without nursing caries. Pediatr Dent 21: 409-416.

37. Derkson GD, Pontl P (1982) Nursing Bottle Syndrome; prevalence and etiology in a non-fluoridated city. J Can Dent Assn 6: 389-393.

38. Wyne AH, Adenubi JO, Shalan T, Khan N (1995) Feeding and socioeconomic characteristics of nursing caries children in a Saudi population. Pediatr Dent 17: $451-454$.

39. Weerheijm KL, Uytendaele-Speybrouck BFM, Eurwe HC, Groen HJ (1998) Prolonged demand breast-feeding and nursing caries. Caries Res 32: 46-50.

40. Pine CM, Adair PM, Nicol AD, Burnside G, Petersenet PK, et al. (2004) International Comparisons of health inequalities in childhood dental caries. Community Dent Health 21: 121-130.

41. Thakur R, Singh MG, Chaudhary S, Manuja N (2012) Effect of mode of delivery and feeding practices on acquisition of oral Streptococcus mutans in infants. In J of Pediatr Dent 22: 197-202.

42. Arora A, Michelle A, Matthew W, Hilton G, Anthony S, et al. (2012) 'I can't relate it to teeth': a qualitative approach to evaluate oral health education materials for preschool children in New South Wales, Australia. Int J of Pediatr Dent 22 302-309. 
Citation: Abu Hamila NAA (2013) Early Childhood Caries and Certain Risk Factors in a Sample of Children 1-3.5 Years in Tanta. Dentistry 4: 180. doi:10.4172/2161-1122.1000180

43. Grytten J, Rossow I, Holst D, Steele L (1988) Longitudinal Study of dental health behaviors and other caries predictors in early childhood, Community Dent Oral Epidemiol 16: 356-359.

44. Wigen TI, Espelid I, Skaare AB, Wang NJ (2011) Family Characteristics and Caries Experience in Preschool Children. A Longitudinal Study from Pregnancy to 5 Years of Age. Community Dent Oral Epidemiol 39: 311-317.

45. Rajab LD, Petersen PE, Bakaeen G, Hamdan MA (2002) Oral Health Behaviour of Schoolchildren and Parents in Jordan. Int J Paediatr Dent 12: 168-176.
46. Szatko F, Wierzbicka M, Dybizbanska E, Struzycka I, Iwanicka-Frankowska E (2004) Oral Health of Three-Year-Olds and Mothers' Oral Health-Related Knowledge. Community Dent Health 21: 175-180.

47. Reisine S, Douglass J (1998) Psychological and behavioral issues in early childhood caries. Community Dent Oral Epidemiol 26: 32-44.

48. Okada M, Kawamura M, Kaihara Y, Matsuzaki Y, Kuwahara S, et al. (2002) Influence of parents Oral health behavior on Oral Health Status of their School Children: An exploratory study employing a causal modeling technique. Int J Pediatr Dent 12: 101-108. 